\title{
Estado de excepción y repúblicas policiales ${ }^{1}$
}

\section{State of emergency and police republics}

\author{
Jessica Enith Fajardo Carrillo ${ }^{2}$
}

\section{Resumen}

Este escrito busca servir de sustento teórico a un estudio que está enmarcado en la filosofía política contemporánea y las teorías críticas de la violencia de Estado. Se hace un acercamiento al concepto de Estado de excepción y presenta los riesgos que corren los Estados en convertirse en repúblicas policiales al ser gobernadas por las oligarquías. Para argumentar la afirmación, se conceptualiza el Estado republicano y la sociedad democrática con Jacques Rancière (2012). Luego se tratan las nociones de incapacidad de previsión de los gobiernos y el Estado de excepción, trabajadas por Mario Daniel Serrafero (2013). En un tercer momento, retoma los conceptos de razón de Estado con Friedrich Meinecke (1997) y la reglamentación del uso de la violenciay las operaciones de policía a partir de Walter Benjamin (2009) y Giorgio Agamben (2010).

Palabras clave: Estado republicano; Incapacidad de previsión; Estado de excepción; Operaciones de policía; Repúblicas policiales

\begin{abstract}
This paper seeks to serve as theoretical support for a study that is framed in contemporary political philosophy and critical theories of state violence. It approaches the concept of the state of emergency and presents the risks that states run in becoming police republics when governed by oligarchies. In order to argue the assertion, the republican State and democratic society are conceptualized with Jacques Rancière (2012). Then, the notions of the inability to foresee of governments and the State of Emergency, worked on by Mario Daniel Serrafero (2013), are dealt with. In a third moment, he resumes the concepts of reason of State with Friedrich Meinecke (1997) and the regulation of the use of violence and police operations starting from Walter Benjamin (2009) and Giorgio Agamben (2010).

Keywords: Republican state; Disability; Incapacity of foresight; State of emergency; Police operations; Police republics.
\end{abstract}

\footnotetext{
${ }^{1}$ Trabajo recibido el 01/06/2019. Aceptado el 30/11/2019.

${ }^{2}$ Ministerio de Gobierno y Economía de la Ciudad de Buenos Aires. Contacto: lumi.jessica@gmail.com
} 


\section{Introducción}

Para examinar la violencia por excepción, se elabora un esquema analítico, seleccionando y cruzando conceptos pertenecientes a los estudios filosóficos de estética y política -con Jacques Rancière (2012)- y de biopolítica -con Giorgio Agamben (2010)-, las teorías críticas de la Escuela de Frankfurt -con Walter Benjamin (2009) y las teorías de estado -con Mario Daniel Serrafero (2013) y Friedrich Meinecke (1997). En el siguiente gráfico se observa el detalle de la analítica de los conceptos a desarrollar:

\section{Gráfico 1: Analitica del Estado de excepción y las Repúblicas Policiales}

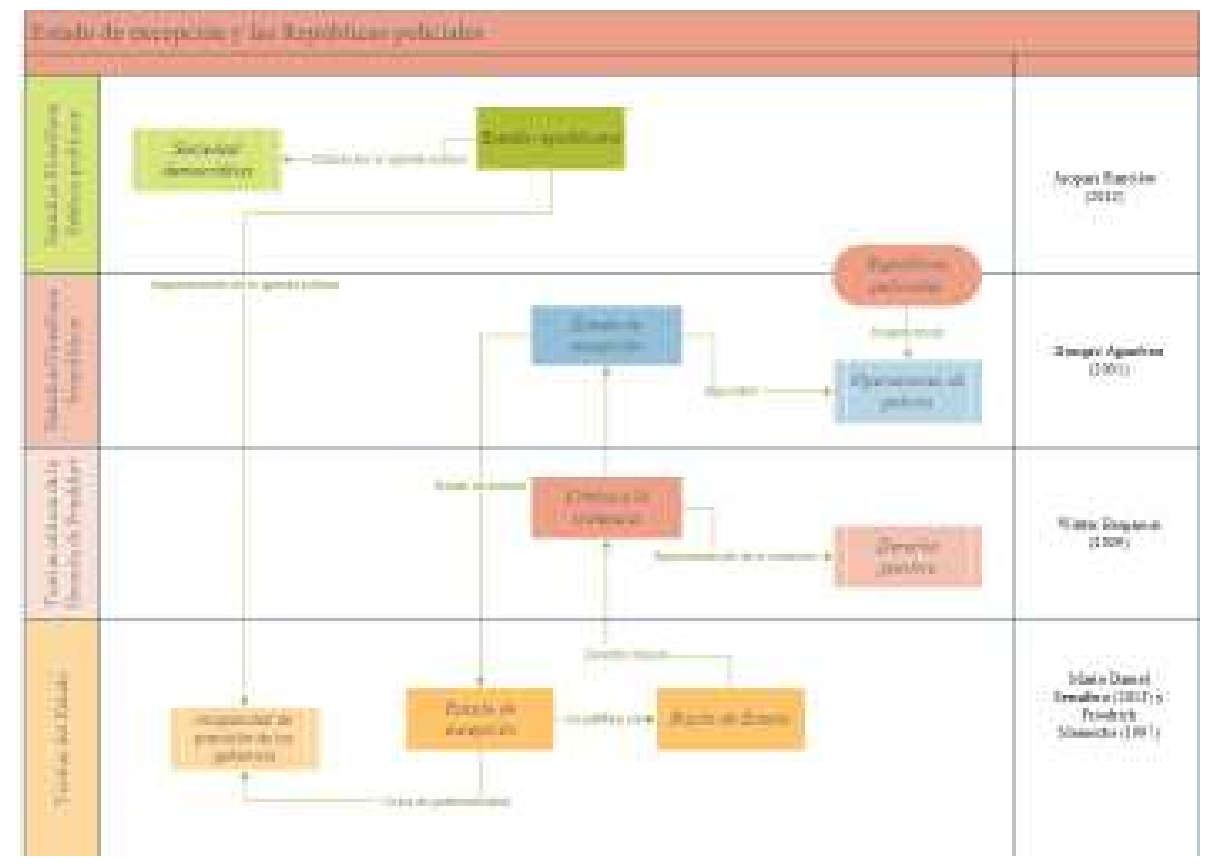

Teniendo en cuenta el esquema, este escrito analiza teóricamente el Estado de excepción en las repúblicas, partiendo de la siguiente tesis: los Estados administrados por las oligarquías entran en conflicto con la sociedad democrática, perdiendo su capacidad de previsión al no atender lo que ella demanda. Cuando se cierra el debate político, el Estado acapara la agenda pública y ante este conflicto, se invoca la crisis de gober- 
nabilidad para declarar el Estado excepción y trae el riesgo de imponerse un control policial con la reglamentación de violencia. Para sustentar esta tesis, el texto desarrolla tres argumentos:

1. Disputa presentada por Rancière (2012) entre los Estados republicanos y la sociedad democrática, con el fin de analizar los conceptos de república, democracia y agenda pública y presentar las condiciones institucionales que lleva a la crisis de gobernabilidad.

2. Relación entre el problema del acaparamiento de la agenda pública expuesto por Rancière (2012) y la incapacidad de previsión trabajada por Serrafero (2013), con el fin de tratar los conceptos de crisis de gobernabilidad y Estado de excepción y exponer las condiciones que pueden llevar a una república a accionar de forma policial.

3. Comparación entre los planteamientos de Meinecke (1997) sobre la violencia por excepción y los estudios sobre violencia y policía propuestos por Benjamin (2009) y Agamben (2010) con el fin de proponer la noción de repúblicas policiales como una expresión de la reglamentación de la violencia por excepción.

A continuación, se presentan los argumentos en tres secciones, donde se relacionan y se comparan los conceptos introducidos en esta primera parte del texto.

\section{Los actos democráticos y la demanda por el orden}

En esta sección se trabaja la contradicción entre los Estados republicanos y la sociedad democrática y cómo la tradición política representa las acciones democráticas. Para esto se hace una breve reseña de las reflexiones hechas por Rancière (2012) en el libro El Odio a la Democracia. En este texto, revela el carácter político de los actos democráticos, que rompen los límites institucionales que distinguen lo público de las experiencias privadas. Bajo este umbral, emerge la democracia ilimitada, que lleva a las sociedades a ocuparse de los asuntos públicos, provocando una tensión con las instituciones estatales. Con el fin de mantener la autoridad científica de ocuparse de los asuntos públicos, los gobiernos afirman que la sociedad no posee las facultades magistrales de subvertir las tradiciones de gobierno, justificando la permanencia de un poder que mantenga las tradiciones republicanas. 
Para Rancière (2012), la teoría política entiende la participación ilimitada como un riesgo, ya que los asuntos públicos pueden caer en manos de los caprichos individuales (propiedad inmanente a las sociedades democráticas). Bajo esta lógica, las repúblicas demandan que la sociedad se limite para que los asuntos públicos no caigan en sus manos, ya que es entendida como degenerada e incapaz. De manera que, se propone establecer un orden policial para imponer límites a una sociedad que amenaza la administración de los Estados y de las riquezas. Según Rancière, Platón define la república como el gobierno que garantiza que los elegidos (por los dioses y sus riquezas) guíen el rebaño humano contra sus caprichos individuales. Cuando se demanda el orden de la república, la tradición política afirma que no hay suficientes privilegios que puedan satisfacer, en su totalidad, los deseos individuales de la sociedad democrática, considerada una humanidad pueril que necesita la guía de una élite erudita.

Ante la ausencia de principio de orden, Rancière (2012) afirma que la tradición platónica entiende la democracia como un problema, pues el gobierno está en manos del hombre privado y egoísta, siendo así «propiamente la inversión de todas la relaciones que estructuran a la sociedad humana: los gobernantes tienen aire de gobernados, y los gobernados, de gobernantes» (p. 57). El orden se subvierte y la élite gobernante es sometida al mando de una sociedad percibida como incapacitada de autogobernarse. Rancière presenta así el principio de la democracia: la subversión social que la hace política, ya que carece de una propiedad que mantiene el orden (es renovadora); entonces infiere que el conflicto reside cuando los Estados pretenden sostener el orden que mantiene la tradición de concebir a los gobernantes comocapaces y a los gobernados como incapaces. En un sentido más fáctico, se demanda un orden donde los gobernantes justifican sus títulos por su superioridad de nacimiento (apellido) y por superioridad en las actividades productivas (riquezas). Rancière (2012) entiende este tipo de repúblicas como Estados oligárquicos.

\section{La cuestión de la agenda pública y la incapacidad de previsión}

En este segundo apartado continúa exponiéndose el trabajo de Rancière para relacionar sus definiciones con los planteamientos de Mario Daniel Serrafero (2013) en su texto Politica y excepción. Rancière (2012) 
explica que el acaparamiento de la cosa pública se da a través de la alianza entre la oligarquía estatal y la oligarquía económica. Sin embargo, el poder de la soberanía popular y de las libertades individuales limita el acaparamiento de los asuntos públicos, provocando una disputa por agenda pública entre las repúblicas y la sociedad democrática. Para los Estados oligárquicos los asuntos públicos y humanos se convierten en elementos gestionables que son racionalizados por leyes irrefutables, por lo tanto: «quienes luchan por defender un servicio público, un sistema de legislación laboral, un régimen de indemnización por desempleo o un sistema de jubilaciones, serán siempre acusados, aun si su lucha va más allá de sus intereses particulares» (p.121).

La ocupación institucional de la agenda pública hace de los Estados gestores de lo público, sin garantizar escenarios de construcción política con las sociedades democráticas. Para Mario Daniel Serrafero (2013), es habitual que los Estados contemporáneos se encuentren en conflictos o emergencias, ya que las instituciones no responden a los desafíos fácticos y caen en un estado de anomia. Bajo esta situación, el Estado de derecho se resiente, en tanto el marco normativo no responde a las contingencias fácticas, provocando los llamados problemas de gobernabilidad. Para evitar la anomia, según Serrafero, es necesario que el Estado obre «en plenitud dotando al sistema social, político y económico de previsibilidad» (p. 26).

Relacionando los conceptos trabajados hasta ahora, se plantea la siguiente afirmación: si los gobiernos republicanos cierran la agenda pública y no consideran las contingencias fácticas de las sociedades democráticas, pierden su capacidad de previsión, ya que la estructura normativa se construye bajo los criterios de la oligarquía estatal y económica. En este sentido, las demandas de las sociedades democráticas se convierten en contingencias no previstas por las instituciones republicanas que gestionan los asuntos públicos y humanos.

Un Estado dotado de previsibilidad tiene la capacidad de reformar su estructura para evitar ambigüedades y anticipar el comportamiento de los organismos públicos ante los desafíos fácticos de la sociedad democrática. Sin embargo, al carecer de previsibilidad se hace un uso especulativo del término crisis de gobernabilidad, enfatizando sobre la «expansión natural del poder gubernamental» y situando el concepto de poder sobre el derecho. De manera que, la crisis de gobernabilidad es «un concepto que encubre y obra como justificación a un hecho esperable y no 
siempre saludable de la naturaleza política», este hecho es el Estado de excepción (Serrafero, 2013, p. 25).

Para tratar el concepto de Estado de excepción se retomarán los conceptos trabajados por Serrafero (2013), donde se hace una revisión conceptual de la excepción desde Carl Schmitt y Giorgio Agamben con el fin de situar este hecho como la reglamentación de un estado de anomia, que anula el ordenamiento jurídico (un hecho variable según el tipo de Estado). Todo sistema jurídico contempla situaciones extraordinarias que van más allá de la normalidad institucional. Estas situaciones son comprendidas como de necesidad o emergencia y la única forma de enfrentarlas es suspendiendo el ordenamiento jurídico, ya que «algunos órganos se revisten de poder incrementado o porque la ciudadanía ve restringidos sus derechos y garantías» (Serrafero, 2013, p. 6).

Bajo este panorama, es preciso preguntarse iquién decide la excepción y bajo qué criterios se establece? Al situar al Soberano como agente decisivo, Schmitt muestra las limitaciones del pensamiento político en asuntos de emergencia y ordenamiento jurídico, pues la suerte del Estado y del poder descansa en la decisión del soberano. De esta forma, la decisión se sobrepone sobre el ordenamiento jurídico al considerarse el Estado de excepción como una necesidad racional ante situaciones de emergencia (Serrafero, 2013). Según el pensamiento político, el soberano también decide si una situación es extraordinaria o no; no hay una reglamentación que rija el criterio del soberano, ya que la norma no posee capacidad de previsión. De esta forma, Serrafero muestra el riesgo del realismo político: «por cierto la riqueza del pensamiento de Schmitt excede su 'Teología Política'. Su perspectiva casi fatalmente inmersa en lo fáctico deviene inevitablemente en un realismo político puro que deja fuera de todo juego a la norma y al derecho» (Serrafero, 2013, p. 22).

Giorgio Agamben expone la insuficiencia teórica del Estado de excepción, en cuanto está reglamentado por el orden legal una anomia, una laguna jurídica ante una situación de facto que supera el orden jurídico. Si es algo que no está previsto por el orden jurídico ¿́por qué está reglamentado? La respuesta de Agamben es la siguiente:

En verdad, el estado de excepción no es ni externo ni interno al ordenamiento jurídico, y el problema de su definición concierne precisamente a un umbral, o a una zona de indiferenciación, en el cual dentro y fuera no se excluyen sino que se indeterminan (Citado en Serrafero, 2013, p. 16) 
El Estado de excepción es un espacio vacío del derecho y no constituye una necesidad jurídica originaria, es un espacio sin derecho. Los Estados se encuentran en una contradicción, ya que se reglamenta un estado de anomia que rompe todo orden jurídico y es el concepto de Estado de excepción lo que garantiza la relación entre la anomia y el derecho.

Teniendo en cuenta los conceptos relacionados en esta sección y la exposición del concepto de Estado de excepción, se plantea la siguiente afirmación, que sirve de argumento a la tesis formulada en la primera parte del texto: al considerarse la excepción un espacio intermedio sin derecho, declararlo implica servirse de cualquier medio para mantener unas formas de gobierno, que supone responder a una necesidad jurídica originaria. El uso del Estado de excepción muestra la naturaleza de una figura que es invocada ante las llamadas crisis de gobernabilidad, provocadas por la incapacidad de previsión al acaparar la agenda pública y no atender las demandas de la sociedad democrática. Las disputas por los asuntos públicos son entendidas como riesgos, saliendo del plano de gobernabilidad, más no del orden jurídico. De esta forma, este riesgo de gobernabilidad es interpretado como una situación de emergencia que lleva a la suspensión de los derechos y garantías que la sociedad democrática ha conquistado. Ahora, las repúblicas contemporáneas, reclaman el control y la gestión de lo público, por medio de medidas excepcionales.

Para analizar el uso del Estado de excepción Serrafero (2013) examina el concepto de exceptocracia, un neologismo que hace alusión al gobierno por excepción, en donde el orden jurídico se ve afectado por una práctica que se hace regular en los Estados contemporáneos. Bajo esta lógica, la excepción se reglamenta, permitiendo que las instituciones coexistan con el Estado sin derecho:

El argumento de la excepción permite el infinito virar de rumbo pretendiendo que es sólo eso, una excepción, cuando en realidad se convierte en puro acontecer. Si el hecho extraordinario, no previsto y que asalta al ordenamiento jurídico estaba en la base de justificación de la excepción, ahora la excepción abarca hechos ordinarios (Serrafero, 2013, p. 29)

Cualquier hecho puede ser tratado como una emergencia, siempre que el estado de anomia esté reglamentado y sea el mismo derecho. Este fenómeno pone al desnudo la política o lo que Rancière (2012) denominaría el Estado policial, que confunde el derecho con el hecho de 
atender con métodos excepcionales problemas de gobernabilidad. Para Serrafero (2013) la reglamentación de la excepción puede hacer de los Estados entes administrativos y no legislativos. Y es en este punto donde se bifurca el pensamiento; por un lado, están aquellos que justifican la legalidad y orden jurídico y, por otro, aquellos que justifican el realismo político.

\section{Realismo político y reglamentación de la violencia}

En esta tercera sección se explican y se comparan dos formas de abordar la violencia por excepción: por un lado, se expone la perspectiva del realismo político de Friedrich Meinecke (1997) en su texto La idea de la razón de Estado en la edad moderna; luego se trabajan los estudios de Giorgio Agamben (2010) en su texto Medios sin fin y de Walter Benjamin (2009) en su ensayo Para una critica de la violencia.

Lo que hoy se concibe como Estado, parte del uso que los modernos hicieron de la palabra; esto marcó unas formas históricas que definieron su razón y su obrar. En distintos momentos de la historia, el uso de la palabra Estado se caracterizó por expresar «una autoridad diferenciada de gobernantes y gobernados» (Skinner, 2003, p. 45). Pensar en una autoridad trascendente llevó a pretender definir el espíritu del Estado, como los principios universales de su obrar, un ehtos basado en «El Bien del Estado y de la comunidad nacional» acompañado por «otros valores elevados que piden para sí una vigencia incondicionada» (Meinecke, 1997, pp. 4-5). Sin embargo, el obrar de esa autoridad trascendente no siempre se vio regido por su espíritu, también estuvo motivado por su naturaleza evocada a la voluntad de poder. Bajo la necesidad de mantener con vida al Estado, en momentos de amenaza, toma el poder y rompe con los límites que constituyen la ley moral y el derecho.

Si bien los Estados modernos no reconocen como poder absoluto las autoridades temporales, el Estado se vuelca sobre sí mismo para servirse de ciertos medios y defender el poder que el magisterio los faculta. En defensa del poder público, el Estado retorna a su propia naturaleza y no a los principios universales. Por necesidad natural y en contra de las amenazas, las instituciones de poder obran por medio de la violencia:

aunque solo sea por la utilización del medio, para ella indispensable, de la guerra, la cual, pese a todas las formas jurídicas de que quiera 
revertírsela, significa siempre la penetración del estado de naturaleza a través de las normas de la cultura. El Estado tiene, al parecer, que pecar. (...) He aquí el más terrible y pavoroso hecho de la historia: que no es posible etificar radicalmente aquella comunidad humana que abarca para su protección y fomento a todas las demás (Meinecke, 1997, pp. 13-14)

Teniendo en cuenta el trabajo que hace Meinecke sobre la violencia por excepciónse infiere que el pensamiento político construye una racionalidad que naturaliza la excepción, argumentando que la naturaleza del Estado lo llevará a servirse de cualquier medio para mantener el poder. De esta manera, el poder que impera en las denominadas exceptocracias no está limitado por el orden jurídico.

Giorgio Agamben (2010) revisa el papel de la policía en los Estados de excepción; contrario a lo que la tradición política afirma.El autor señala que la policía deja de cumplir un rol meramente administrativo en la ejecución del derecho y remarca que es el momento cuando se muestra al desnudo, pues, en situaciones de excepción la frontera entre violencia y derecho se desdibuja y encuentra su síntesis en el soberano: «Según la antigua costumbre romana, nadie, por ninguna razón, podía interponerse entre el cónsul dotado de imperium y el licor más cercano, portador del hacha sacrificial (con la que se lleva a cabo la ejecución de la sentencia de pena capital)» (Agamben, 2010, p 90). El soberano es quien marca el punto de distinción entre violencia y derecho, dejando a la policía con facultades excepcionales, en donde su obrar encuentra justificación en la seguridad y el orden público. En palabras de Walter Benjamin:

Es completamente falso afirmar que las finalidades del poder de policía sean siempre idénticas o incluso estén simplemente vinculadas con las del resto del derecho. El derecho de «policía» indica precisamente el punto en que el Estado, sea por impotencia, sea por las conexiones inmanentes a todo orden jurídico, ya no puede garantizar, por medio de este orden, los objetivos que desea conseguir a toda costa (Citado en Agamben, 2010, p. 90)

Trabajados estos conceptos y con el fin de relacionar las dos primeras secciones del escrito, se plantea la siguiente afirmación: la impotencia del Estado se traduce en la incapacidad de previsión al acaparar la agenda pública, provocando situaciones de disputa con la sociedad democrática. Esto genera que los Estados declaren crisis de gobernabili- 
dad, al verse sumergidos en las demandas de la sociedad democrática y en un orden jurídico que contempla los derechos y garantías que ésta ya ha conquistado. Siguiendo los principios del republicanismo, los Estados reclaman ocuparse de la agenda pública, arguyendo la imposibilidad de subvertir las formas tradicionales de administración: los gobernantes no pueden ser gobernados por una sociedad (considerada ilimitada e incapaz). Es en ese momento cuando se decide suspender el orden jurídico bajo el Estado de excepción, un momento que es reglamentado y donde desaparecen los límites entre violencia y derecho. La policía se convierte en el derecho y se abalanza sobre todo aquel que se atreva a subvertir las formas tradicionales de gobierno.

Para Agamben (2010), el soberano (quien decreta la excepción) está en el mismo plano de su verdugo, pues en situaciones de excepción, se despliegan operaciones de policía (metódicas y mortíferas). Por esa razón se crean abstracciones de adversarios o amenazas, que son juzgados como criminales:

A nosotros nos ha sido dado, sin embargo, ver cómo el enemigo, siguiendo un proceso iniciado a finales de la Segunda Guerra Mundial, es, en un primer paso, excluido de la humanidad civilizada y considerado como criminal. Y sucesivamente pasa a ser lícito aniquilarle con una «operación de policía» que no está obligada al respeto de ninguna regla jurídica (Agamben, 2010, p. 92)

Por lo tanto, es necesario inferir que: el Realismo Político justifica la violencia por excepción con la necesidad natural de los Estados, entendido como un fenómeno de necesaria crueldad. El problema descansa cuando desaparece la frontera entre el derecho y la violencia y cuando se reglamentan las operaciones de policía. Walter Benjamin (2009), en su ensayo Para una critica a la violencia, muestra cómo las figuras históricas del Estado de derecho y de excepción traen consigo la violencia sobre los hombres.

Si la justicia es el criterio de los fines (para el uso de la violencia), la legalidad es el criterio de los medios. Pero, si se prescinde de esta oposición, las dos escuelas se encuentran en el común dogma fundamental: los fines justos pueden ser alcanzados por medios legítimos. Los medios legítimos pueden ser empleados al servicio de fines justos. El derecho natural tiende a «justificar» los medios legítimos con la justicia de los fines, el derecho positivo a «garantizar» la justicia 
de los fines con la legitimidad de los medios. (Benjamin, 2009, pp. 114-115)

Para Benjamin (2009), la crueldad de la violencia no es asunto que está presente exclusivamente en el derecho natural, se puede ver cuando el soberano, como primer legislador, acude a la crueldad con el fin de cumplir una promesa justa. Los dos parten de un fundamento común y es el uso de la violencia. Los hombres están sometidos a la violencia tanto en el gobierno de la ley como en el gobierno de los hombres. En el derecho positivo, la necesidad natural de la violencia es cristalizada con el fin de garantizar la ley y su justicia, siendo así el uso de la violencia un acto legítimo de fuerza. Entonces, la violencia termina siendo aplicada, bajo la lógica formal de la doctrina de derecho, que arriesga a convertirse en una República policial manejada por una fuerza ciega, desprovista de cualquier juicio moral.

\section{Conclusiones}

Benjamin señala un punto que sustenta la conclusión de esta monografía: advierte que la violencia no solo está presente en los momentos excepcionales de necesaria crueldad; la violencia también se presenta siempre que esté reglamentada en el orden jurídico. Las operaciones policiales se hacen ilimitadas y son cristalizadas en el Estado de excepción como un impulso arcaico legislador que lleva a modificar el orden jurídico. La reglamentación de las operaciones de policía se hace necesaria en momentos de excepción, en donde cualquiera puede ser el criminal: «De lo que no se dan cuenta los jefes de Estado, que han lanzado con tanta diligencia a la criminalización del enemigo, es de que esta misma criminalización puede volverse en cualquier momento contra ellos» (Agamben, 2010, p. 92). Partiendo de este aporte se concluye que, para preservarse a sí mismo, el Soberano debe reglamentar la violencia y cristalizarla en un nuevo orden jurídico. Es en este momento cuando emergen las repúblicas policiales que mantendrán con una violencia ilimitada el gobierno y el manejo de la agenda pública, momento cuando la violencia pasa de ser una experienciaexcepcional a ser una medida legal. 


\section{Referencias bibliográficas}

Agamben, G. (2010). Medios sin fin. Valencia, España: Pre-textos.

Benjamin, W. (2009). Para una crítica de la violencia. En Benjamin, W. Conceptos de filosofía de la historia, pp. 113-138. Buenos Aires, Argentina: Terramar.

Meinecke, F. (1985). La esencia de la razón de estado. En Meinecke, F. La idea de la razón de Estado en la edad moderna, pp. 3-23. Madrid, España: CEPC.

Rancière, J. (2012). El odio a la Democracia. Buenos Aires, Argentina: Nómadas.

Serrafero, M.D. (2013). Politica y excepción. Buenos Aires, Argentina: Academia Nacional de Ciencias Morales y Políticas.

Skinner, Q. (2003). El Nacimiento del Estado. Buenos Aires, Argentina: Gorla. 